\title{
Model of Organizational Learning Culture on Knowledge Sharing Behavior
}

\author{
Sabaruddin Sondeng ${ }^{1}$, Nurwati ${ }^{2}$, Endro Sukotjo ${ }^{3} \&$ Sriwiyati Maharani $^{4}$ \\ ${ }^{1,3}$ Doctoral Program of Management Science, Postgraduate of Halu Oleo University, Kendari, Indonesia \\ ${ }^{2,4}$ Economic and Business Faculty, Halu Oleo University, Kendari, Indonesia \\ Correspondence: Sabaruddin Sondeng, Doctoral Program of Management Science, Postgraduate of Halu Oleo \\ University, Kendari, Southeasth Sulawesi, Indonesia. E-mail: sabaruddinsondeng55@gmail.com
}

Received: September 22, 2020

doi:10.5539/ijbm.v15n11p184
Online Published: October 25, 2020

\begin{abstract}
The old research revealed that job attitudes were not correlated by a knowledge sharing behavior. This research develops to investigate the role organizational learning culture in context relations forming knowledge sharing behavior. Using a survey, 100 person graduates from Work Training Center involved as a respondent in this project from periods 2019 to 2020 . This research was conducted with a quantitative method's include variables job attitude, OCB, organizational learning culture, and knowledge sharing behavior. The data were measured by likert scale from 1 to 5 and collected by using a questionnaire measure. Research model develops with job attitudes as an independent variable, OCB as a mediation variable, organizational learning culture as a moderator variable and knowledge sharing behavior as a dependent variable was supported by SmartPLS3. The output investigation reveals that job attitude is a significantly factor linked to knowledge sharing behavior, and also correlated to organizational citizenship behavior. The other situation create that organizational citizenship behavior was not a significant variable on knowledge sharing behavior, and also OCB was not a mediation variable for knowledge sharing behavior. The exploration discloses that organizational learning culture has a moderate significant weather OCB towards knowledge sharing behavior or job attitude towards OCB, but insignificant for job attitudes on knowledge sharing behavior. Study concluded that job attitude has a significant outcome on $\mathrm{OCB}$ and knowledge sharing behavior. Organizational learning culture provides a strengthening of the association between job attitudes towards OCB and the association between OCB and knowledge sharing behavior. The study gives a new contribution that job attitudes affect both on OCB and on knowledge sharing behavior and organizational learning culture moderate job attitudes on OCB and OCB on knowledge sharing behavior, but not moderate job attitudes on knowledge sharing behavior. This study has limitations on several indicators of OCB and organizational learning culture while there are still other indicators, so the researcher recommends the necessity to practice other indicator that are not covered as a new research agenda in future. The results of the study indicate the direct effect of job attitudes on knowledge sharing behavior is still weak, so the researcher suggested a future research to test the organizational learning culture as a moderator variable that can provide strengthening of knowledge sharing behavior in other sectors such as in business or public sectors.
\end{abstract}

Keywords: job attitudes, organizational citizenship behavior, organizational learning culture, knowledge sharing behavior

\section{Introduction}

\subsection{Introduce the Problem}

Theory of reasoned action (TRA) was adopted by Teh and Sun (2012) studying knowledge sharing behavior. The results show that knowledge sharing behavior is influenced by organizational citizenship behavior, job involvement and job satisfaction which are the main components of work attitudes. A knowledge-sharing behavior model (Teh and Sun, 2012) was developed to study knowledge-sharing behavior (Husain, 2015). Husain (2015) states that job attitudes have a significant influence on knowledge sharing behavior through OCB which is in each individual and is strengthened by the existence of an organizational learning culture. This study gave birth to an organizational learning model which states that organizational learning culture has a very important role in strengthening $\mathrm{OCB}$, and $\mathrm{OCB}$ itself has a very strategic role in mediating the relationship between job attitudes and knowledge sharing behavior (Husain, 2015; Husain and Husain, 2016; Husain et.al, 
2017).

Organizational learning model (OLM) (Husain et.al, 2017) differs from model Teh and Sun (2012) which state that OCB is not a mediator of job attitudes. However, this model explains the role of OCB as a mediator of job attitudes even though the effect is still small (Husain, 2015; Husain and Husain, 2016; Husain et.al, 2017). Similarly, organizational learning culture is a factor that strengthens the relationship between OCB and knowledge sharing behavior (Husain, et.al., 2015; Husain et.al, 2017). Nevertheless, the organizational learning model (OLM) is not able to explain the significantly of relationship between job attitudes and knowledge sharing behavior. Thus the main problem of this study is that there is an insignificant relationship between job attitudes and knowledge sharing behavior, while experts state that the relationship between the two variables is very close. Job attitude is considered as a very strategic factor to determine someone's behavior to share knowledge. On the other hand, previous researchers suggested that organizational learning culture has a very strategic role to moderate job attitudes.

Islam et al. (2012); Sorakraikitikul and Siengthai (2014) identified that organizational learning culture as a factor influenced knowledge sharing behavior. Equally, Jo and Joo (2011); Islam et al. (2012) agreed that organizational learning culture has a significant influence on OCB. OCB was also found to be a significant mediator variable on knowledge sharing behavior (Jo and Joo, 2011; Islam et al., 2012; Sadegh, 2015; Husain et. al., 2017). Husain et.al.(2017) defines organizational learning culture as a strategic role for moderate OCB on knowledge sharing and OCB.

\subsection{Aims}

This study aims to:

1. Investigate the relationship job attitudes on OCB and Knowledge Sharing Behavior

2. explore the role of organizational learning culture in moderating work attitudes towards OCB and knowledge-sharing behavior

\section{Literature Review}

\subsection{Job Attitudes and Knowledge Sharing Behavior}

Theory of resoned action (Ajzen and Fisbein, 1971) and the theory of planned behavior (Ajzen, 1991) identify that attitudes do not have a direct effect on knowledge sharing behavior, but intention to behave is a mediator that encouragements knowledge sharing behavior. This declaration is strengthened by the sharing of findings from researchers such as Bock (2002); Lin et al. (2004); Teh and Yong (2011); and Husain et al. (2017), also specified that job attitudes were not linked on knowledge sharing behavior. This conclusion shows job attitude is not a determinant directly affects knowledge sharing behavior. It means that the greater of job attitude level an employee is not a warranty for enlarged knowledge sharing behavior.

However, knowledge sharing behavior model detailed the components of job attitudes as job satisfaction and job involvement have a straight guidance on knowledge sharing behavior (Teh and Sun, 2012). This model is consistent with the judgments of Xue et al. (2011) indicating that attitudes have a direct influence on knowledge sharing behavior. These results indicate that job attitude is a major determinant affects knowledge sharing behavior. It means that the higher job attitude level an employee will increase knowledge sharing behavior.

In construction the verdicts of scholar, job attitudes have a direct influence on knowledge sharing behavior, on the other hand it is also found that job attitudes do not directly affect knowledge sharing behavior, thus attracting the helpfulness of recent research to study the association between job attitudes and knowledge sharing behavior and propose a hypothesis the higher of job work attitude within the individual, the higher knowledge sharing behavior itself, so we formulated as follows:

H1: Job attitudes has a significant effect on knowledge sharing behavior

\subsection{Job Attitudes and $O C B$}

Robbins and Judge (2013) detailed the components of job attitude consist of job satisfaction, organizational commitment and job involvement. Huang et al. (2012) establish job satisfaction as a center effects on OCB in the organization. The same thing was found by Mohammad et al. (2012) indicated that intrinsic satisfaction has a major effect on OCB for organizations. Ueda (2012) expressions work interaction as a main effect on civic virtue and helping behavior. Teh and Sun (2012) also found job involvement and job satisfaction have a significant effect on OCB. Furthermore, Jofreh et al (2014) imply work attitudes as a main aspect forming OCB. Similarly, Husain et al (2017) also found job attitude as a factor influencing OCB. It was relevant Shafazawana et.al. (2016) who found the components of job attitudes such as job satisfaction and organizational commitment have a 
significant influence on OCB. In connection with the findings of these researchers, it provides an indication that job attitude has a significant influence on OCB which means that the higher the individual work, the higher OCB action in the organization.

However, Schappe (1998) states that job satisfaction do not have a significant effect on individual OCB. The same thing was establish by Huang et al. (2012) identified job satisfaction has no significant effect on individual OCB. This result is also consistent with Mohammad et al. (2012) which defines intrinsic satisfaction is not significant towards OCB for individuals. Teh and Sun (2012) also found that organizational commitment did not have a significant effect on OCB. The findings of these experts indicate job attitude component does not have a significant effect on OCB. It is indicating that an increase individual job attitudes does not have an effect on an increase individual OCB.

These previous research findings provide different meanings where previous experts have had a significant influence, but on the other hand, other researchers also found that it is not significant for OCB so that researcher is interested in proposing the following hypothesis:

$\mathrm{H} 2$ : Job attitude has a significant effect on OCB

\section{$2.3 O C B$ and Knowledge Sharing Behavior}

The model of Teh and Sun (2012) originate OCB as a factor encouragement for knowledge sharing behavior. It is similarly with Husain et. al (2017) within organizational learning model (OLM) describing the linkage OCB and knowledge sharing behavior. OCB is drawn as a capital variable for knowledge sharing behavior. Everybody shall share their knowledge if there is OCB in him. Based on these model indicate that OCB is an antecedent for knowledge sharing behavior. Al-Zu'bi (2011) presented the five dimensions of OCB in linkage for knowledge sharing behavior. They were reflected as items forming OCB so knowledge sharing behavior appears. Next, Ramasamy and Thamaraiselvan (2011) describe that simultaneously the five dimensions of OCB in the form of altruism, courtesy, conscientiousness, sportsmanship and civic virtue were significantly related to knowledge sharing. Islam et al. (2012) reveals that OCB has a significant effect on knowledge sharing. Furthermore, Teh and Sun (2012) found that OCB has a significant effect on knowledge sharing behavior. Husain et. Al. (2016) found that OCB has a positive influence on knowledge sharing behavior.

The findings of these experts indicate that an increase in OCB will provide a significant increase in knowledge sharing behavior. However, the knowledge sharing behavior model (Teh and Yong, 2011) states that OCB has an indirect influence on knowledge sharing behavior, so that researchers are interested in proposing the following hypothesis:

\section{H3: Organizational citizenship behavior has a significant influence on knowledge sharing behavior}

Organizational learning model definite that $\mathrm{OCB}$ has a role in mediating the relationship between job attitudes and knowledge sharing behavior (Husain et al., 2017., Husain and Husain, 2016) but inconsistent with Teh and Sun (2012) who initiate OCB as a variable that insignificant within mediate the correlate towards knowledge sharing behavior. Thus, we propose a hypothesis:

H4: Organizational citizenship behavior has a significant influence within mediate on knowledge sharing behavior

\subsection{Organizational Learning Culture}

Jo and Joo (2011) examined the relationship between organizational learning culture and organizational commitment and OCB of Korean workers. The results of the study found that organizational learning culture has a significant influence on OCB. These findings are consistent with Islam (2012) which found that organizational learning culture has a significant effect on OCB. Husain et.al (2016) studied the relationship between organizational learning culture and $\mathrm{OCB}$, the results shows organizational learning culture moderating $\mathrm{OCB}$ to effect significant on knowledge sharing behavior. Issa and Haddad (2008) conducted a study of the relationship between organizational culture and knowledge-sharing behavior. The study reveals organizational culture has a significant effect on knowledge sharing. Goudarzi et al. (2009) conducted a research on the relationship between organizational culture and knowledge management at the director of medical education organizations and concluded that there was no significant relationship between knowledge sharing culture and knowledge creation culture, but there was a significant relationship between knowledge sharing culture and knowledge transfer culture. This study establish the existing culture in form of a culture of sharing knowledge and learning as well as continuous training from the leadership to the most important step towards the creation and transfer of knowledge and the application of knowledge management. Islam et al. (2012) steered a study on the connection between organizational learning culture and knowledge-sharing behavior. Husain et.al (2017) stated that 
organizational learning culture is a moderating variable for OCB that has a significant effect on knowledge sharing behavior. This means that increasing organizational learning culture will strengthen OCB relationships and knowledge-sharing behavior. Islam et.al (2014) initiate organizational learning culture has a significant guidance on job satisfaction. Islam et.al (2014) also reveals organizational learning culture has a significant consequence on job satisfaction and affective commitment. It means, increasing of organizational learning culture will increase the level of job satisfaction and commitment of employees. Thus, we propose a hypothesis:

H5: Organizational learning culture significantly moderates the effect of OCB on knowledge sharing behavior

H6: Organizational learning culture significantly moderates the effect of Job Attitudes on knowledge sharing behavior

H7: Organizational learning culture significantly moderates the effect of Job Attitudes on OCB

\section{Methods}

This research was conducted based on a quantitative approach to 100 graduates at job training centers in Southeast Sulawesi. Data was collected using a questionnaire measured using a Likert scale of $1-5$. The research model was developed using the Path Least Square approach - Structural Equation Modeling (PLS SEM) which is processed with the help of SmartPLS3.0 software

\section{Results}

Reliability of indicators aims to assess whether the indicators of measuring latent variables are reliable or not. A loading value above 0.7 indicates the construct can explain more than $50 \%$ of indicator variance (Wong K.K., 2013; Sarstedt et al., 2017). Table 1 shows the Cronbach's Alpha value of Job attitude, organizational citizenship behavior, organizational learning culture, interaction variable between organizational learning culture and job attitude, interaction variable between organizational learning culture and $\mathrm{OCB}$, and knowledge sharing behavior has a Cronbach's Alpha value $>0.7$ so this model is concluded to be reliable. The Composite reliability value is more than 0.6 of fit expected $>0.6$ (Netemeyer, 2003). The Average Variance Extracted (AVE) is more than 0.5 of fit expected $>0.5$ or more (Wong K.K., 2013, Sarstedt et al., 2017). The value of cross loading is higher than the value of each loading indicator. Testing whether or not multicollinearity occurs between indicators is carried out using the VIF value. The results of the calculation show that all VIF values of the manifest variable are $<10$, it means that there is no multicollinearity in the research model.

Table 1 . Reliability and validity contructs

\begin{tabular}{lllll}
\hline & $\begin{array}{l}\text { Cronbach's } \\
\text { Alpha }\end{array}$ & rho A & Composite reliability & AVE \\
\hline Interaction OLC * OCB & 1.000 & 1.000 & 1.000 & 1.000 \\
Interaction OLC * JA & 1.000 & 1.000 & 1.000 & 1.000 \\
Interaction OLC * JA & 1.000 & 1.000 & 1.000 & 1.000 \\
$\mathrm{JA}$ & 0.75 & 0.790 & 0.84 & 0.52 \\
OCB & 0.82 & 0.86 & 0.87 & 0.56 \\
OLC & 0.80 & 0.82 & 0.86 & 0.55 \\
KSB & 0.72 & 0.82 & 0.84 & 0.65 \\
\hline
\end{tabular}

Source: SmartPLS3, 2020

Note: $\mathrm{JA}=$ Job Attitude

$\mathrm{OCB}=$ organizational citizenship behavior

OLC $=$ organizational learning culture

$\mathrm{KSB}=$ Knowledge Sharing Behavior

\section{Discussion}

Job attitude is a very good perception of the level of dependence on work as a form of work involvement, the level of pleasure in a career as a form of self-satisfaction, emotional level, and a good perception of the feeling of life that will be disturbed if you leave the job profession as a form of implementing commitment to work. The results showed that the effect of work attitudes on knowledge sharing behavior was significant. These findings mean that the significance of changes in work attitudes that exist in individuals will also influence changes in 
knowledge-sharing behavior within the individual. Based on the findings of this study, hypothesis H1 that job attitude has a significant effect on knowledge sharing behavior is acceptable. This finding is in line with Teh and Sun (2012) who state the components of job attitudes were job satisfaction and job involvement have a direct influence on knowledge sharing behavior. This model is also consistent with the findings of Xue et al. (2011) who states job attitudes have a direct influence on knowledge sharing behavior. The results of this study also found a significant influence on OCB so that the proposed H2 hypothesis was also accepted. It is in accordance with the findings of experts who state that job attitudes have a significant effect on OCB (Husain, 2016); Husain et al., 2017; Shafazawana et.al., 2016; Jofreh et al., 2014; Teh \& Sun, 2012; Robbins \& Judge, 2013; Huang et al., 2012; Mohammad et al., 2012). There are several reasons that make someone choose a good job attitude so that it affects an individual's knowledge sharing and OCB behavior, namely: dependence on work indicating that someone is involved in a job. Job performance gives job satisfaction. Pleasure for a career and emotional feelings towards work and life that will be disturbed if leaving work makes a person commit to continue carrying out his current job profession.

OCB is a poor perception of responsibility, involvement in work politics, attendance at meetings, timeliness of work completion, delivery of basic work-related matters, and prior notification of work implementation. The results showed that OCB did not have a significant effect on knowledge sharing behavior at the probability level of 0.05 . These findings suggest that OCB has no influence on knowledge-sharing behavior so that it means that the significance of changes in OCB in individuals will not change knowledge-sharing behavior. Hypothesis $\mathrm{H} 3$ proposes that OCB has a significant influence on knowledge sharing behavior which cannot be proven so it is refuted and rejected. The findings of this study are in line with the previous research of Teh and Yong (2011) who found that OCB has an indirect effect on knowledge sharing behavior. The results also show that OCB has no significant effect in mediating the relationship between work attitudes and knowledge sharing behavior as presented in table 2 so that the hypothesis $\mathrm{H} 4$ proposed in this study cannot be accepted or rejected. The findings of this study are in line with what was stated by Teh and Sun (2012) who found that OCB had an insignificant influence in mediating the relationship between components of job attitudes and knowledge sharing behavior.

Table 2. Significant model

\begin{tabular}{|c|c|c|}
\hline Hypothesis & $\mathrm{T}_{\text {values }}$ & $\mathrm{P}_{\text {Values }}$ \\
\hline Effect of job attitudes (X1) on knowledge sharing behavior (Y) & 1.97 & $0.05^{*}$ \\
\hline Effect of job attitudes (X1) on OCB (X2) & 6.21 & $0.00^{*}$ \\
\hline Effect of OCB (X2) on knowledge sharing behavior $(\mathrm{Y})$ & 0.74 & 0.46 \\
\hline $\begin{array}{l}\text { Mediation effect of OCB (X2) on the relationship job attitudes (X1) and knowledge } \\
\text { sharing behavior (Y) }\end{array}$ & 0.69 & 0.49 \\
\hline $\begin{array}{l}\text { Moderation effect of organizational learning culture }(\mathrm{Z} * \mathrm{X} 1) \text { on the relationship of job } \\
\text { attitude }(\mathrm{X} 1) \text { and knowledge sharing behavior }(\mathrm{Y})\end{array}$ & 0.16 & 0.87 \\
\hline $\begin{array}{l}\text { Moderation effect of organizational learning culture }(\mathrm{Z} * \mathrm{X} 1) \text { on the relationship of job } \\
\text { attitudes }(\mathrm{X} 1) \text { and } \mathrm{OCB}(\mathrm{X} 2)\end{array}$ & 4.30 & $0.00^{*}$ \\
\hline $\begin{array}{l}\text { The moderating effect of organizational learning culture }(\mathrm{Z} * \mathrm{X} 2) \text { on the relationship of } \\
\mathrm{OCB}(\mathrm{X} 2) \text { and knowledge sharing behavior }(\mathrm{Y})\end{array}$ & 2.84 & $0.01 *$ \\
\hline
\end{tabular}

Table 3. Determinant coefficient $R^{2}$

\begin{tabular}{lll}
\hline Variable & $\begin{array}{l}O C B \\
(X 2)\end{array}$ & $\begin{array}{l}\text { Knowledge Sharing Behavior } \\
(Y)\end{array}$ \\
\hline Job Attitudes $(X 1)$ & $0.62^{*}$ & $0.31^{*}$ \\
OCB $(X 2)$ & & 0.11 \\
Mediation OCB (X2) & 0.07 \\
$\begin{array}{l}\text { Moderation Organizational Learning Culture and Job } \\
\text { Attitudes (ZxX1) }\end{array}$ & $0.37^{*}$ & -0.03 \\
$\begin{array}{l}\text { Moderation Organizational Learning Culture and } O C B \\
\text { (ZxX2) }\end{array}$ & $0.37^{*}$ \\
\hline
\end{tabular}

Organizational learning culture is a very good perception of listening to the views of others, spending time building trust as a form of questioning and dialogue and freedom to adjust organizational goals as a form of 
group collaboration. The results showed that the influence of organizational learning culture as a moderating variable has no significant effect on knowledge sharing behavior at the probability level of 0.05 . These findings suggest that changes in the interaction between organizational learning culture and work attitudes do not contribute significantly to knowledge sharing behavior. The hypothesis (H5) proposed organizational learning culture has a significant influence in moderating the relationship between Job Attitudes and knowledge sharing behavior cannot be proven so it is refuted and rejected. However, the results showed that organizational learning culture had a significant influence in moderating job attitudes towards OCB so that the research hypothesis H6 was accepted. The results also found that organizational learning culture has a significant influence in moderating OCB on knowledge sharing behavior so that the proposed H7 hypothesis can also be accepted.

Based on the findings stated above, a training graduates learning model can be built as follows:

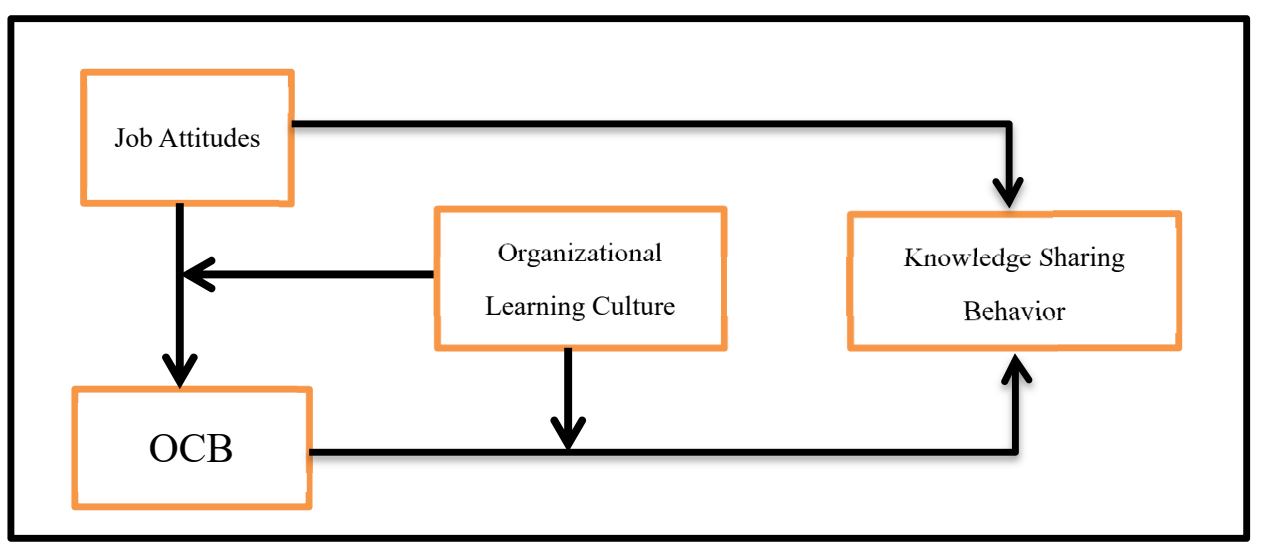

Figure 1. Public Training Implementation Model (PTIM)

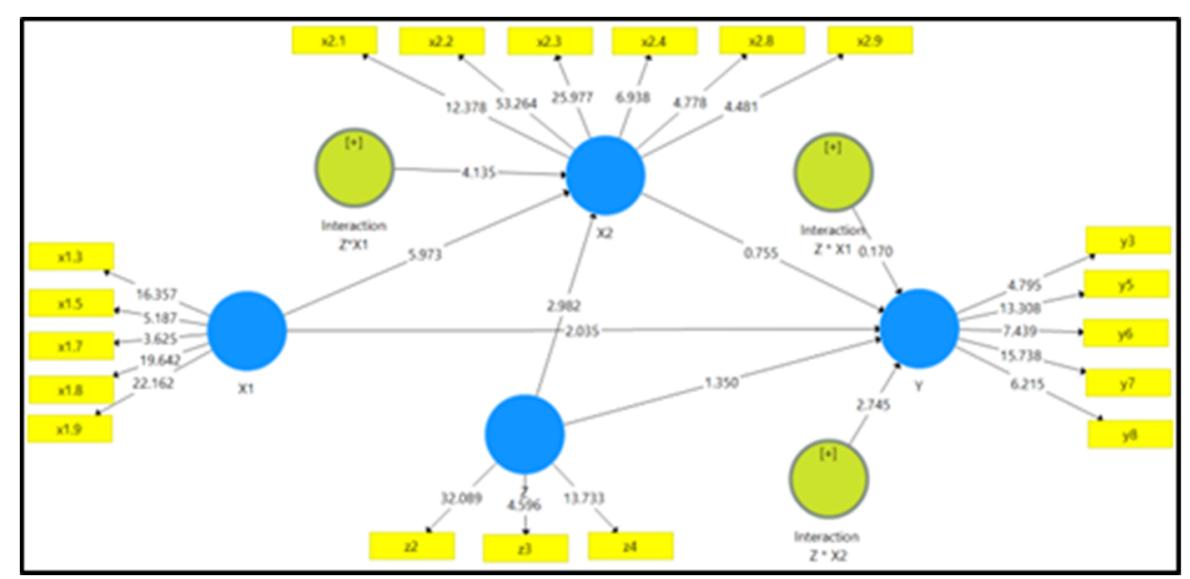

Figure 2. Fit test model 


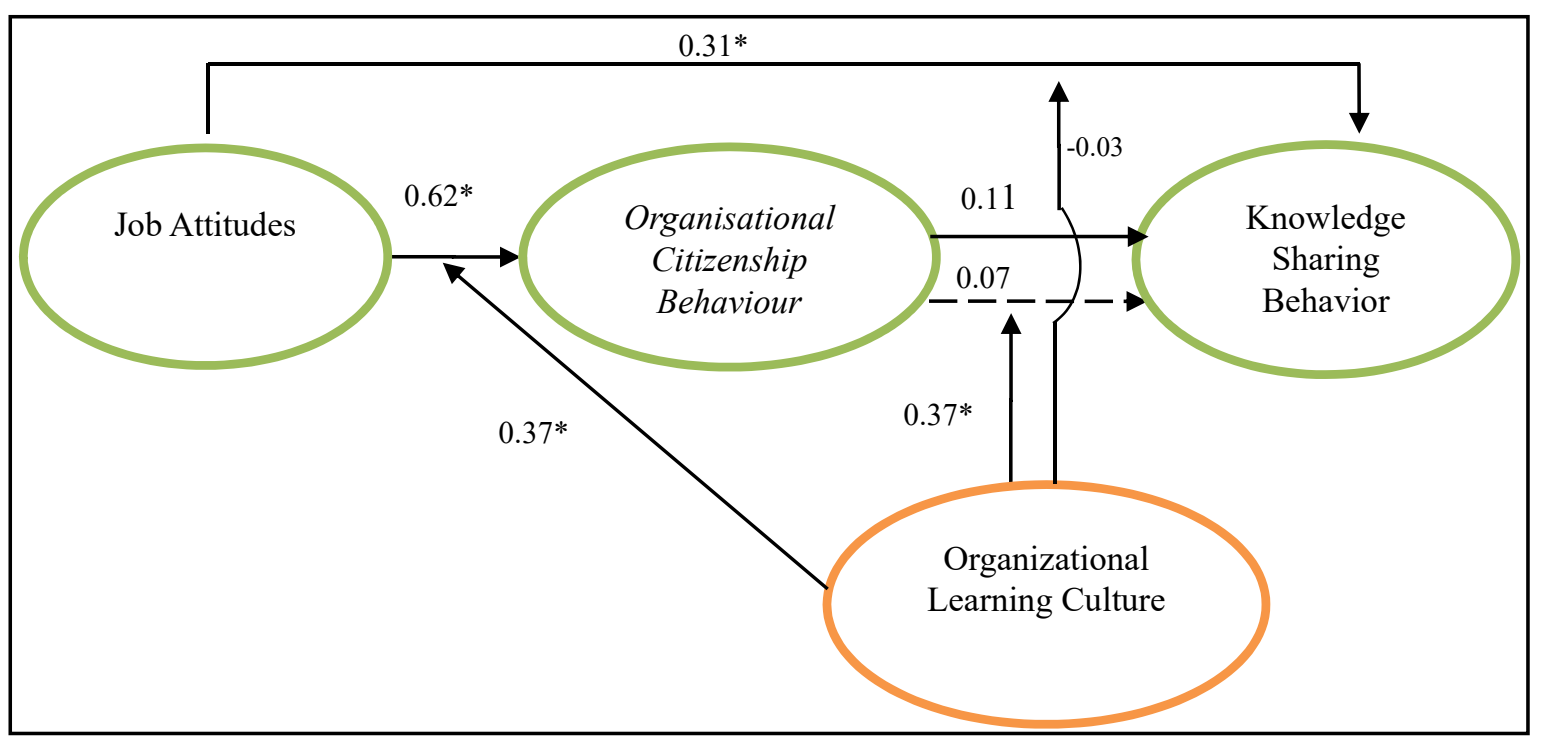

Figure 3. Test result

\section{Limitations and Future Research}

This study did not find a moderating relationship between organizational learning culture and job attitudes towards knowledge-sharing behavior, while it is believed that there is a strong relationship between the two variables so that future research agendas can be carried out by re-examining the relationship model by selecting another research locus. This research is limited to the development of a moderating relationship model for organizational learning culture between the variables of job attitude, OCB, and knowledge sharing behavior, while there are still other mediating relationships that need to be developed so that future research needs to test the mediation relationship model of organizational learning culture. The indicators used from the OCB variable and organizational learning culture are only limited to a few indicators while there are still other indicators that can be used to measure so that future research needs to consider the use of these other indicators. The data used is cross sectional so that the respondents' perceptions allow it to be different at different times and places.

\section{References}

Ajzen, I. (1991). The theory of planned behavior. Organizational Behavior \& Human Decision Processes, 50(2), 179-211. https://doi.org/10.1016/0749-5978(91)90020-T

Al-Zu'bi, H. A. (2011). Organizational citizenship behavior and impacts on knowledge sharing: An empirical study. International Business Research, 4(3), 221-225. https://doi.org/10.5539/ibr.v4n3p221

Bock, G. W., \& Kim, Y. G. (2001). Breaking the myths of rewards: An exploratory study of attitudes about knowledge sharing. Information Resources Management Journal, 15(2), 14-22.

Huang, C. C., You, C.S., \& Tsai, M.T. 2012. A multidimensional analysis of ethical climate, job satisfaction, organizational commitment, and organizational citizenship behaviors. Nursing Ethics, 19(4), 513-529. https://doi.org/10.1177/0969733011433923

Husain, Y. S., Samdin, N. H. (2017). Knowledge sharing behavior, job attitudes, OCB and organizational learning culture. Journal of Administrative and Business Studies, 3(4), 162-170. https://doi.org/10.20474/jabs-3.4.1

Husain, S.N. and Husain, Y.S. 2016. Mediating Effect of OCB on Relationship between Job Attitudes and Knowledge Sharing Behavior. International Journal of Science and Research (IJSR), 5(1).

Husain, Y. S., Sarita, B., Syarifuddin, D. T. (2015). The Role of Organizational Learning Culture to Organizational Citizenship Behavior toward Knowledge Sharing Behavior. International Journal of Science and Research (IJSR), 4(12).

Fishbein, M., \& Ajzen, I. (1977). Belief, attitude, intention, and behavior: An introduction to theory and research. Reading, MA: Addison-Wesley Publishing Company.

Islam, T., Anwar, F., Khan, S. U. R., Rasli, A., Ahmad, U. N. B. U., \& Ahmed, I. (2012). Investigating the 
mediating role of organizational citizenship behavior between organizational learning culture and knowledge sharing. World Applied Sciences Journal, 19(6), 795-799.

Islam, Z. M. (2012). The mediating effects of socialization on organizational contexts and knowledge sharing. Journal Knowledge Global, 3(1), 31-48.

Islam, T., Ahmad Kassim, N., Ali, G \& Sadiq, M. (2014). Organizational Learning Culture and Customer Satisfaction: The Mediating Role of Normative Commitment. The Learning Organization, 2(6), 404-392.

Issa, R. R., \& Haddad, J. (2008). Perceptions of the impacts of organizational culture and information technology on knowledge sharing in construction. Construction Innovation, 8(3), 182-201. https://doi.org/10.1108/14714170810888958

Jo, S. J., \& Joo, B. K. (2011). Knowledge sharing: The in $\square$ luences of learning organization culture, organizational commitment, and organizational citizenship behaviors. Journal of Leadership \& Organizational Studies, 18(3), 353-364. https://doi.org/10.1177/1548051811405208

Jofreh, M., Aghaei, T., \& Mamqani, N. B. (2014). Investigating the impact of job attitudes on organizational citizenship behavior and knowledge sharing. Journal of Educational and Management Studies, 4(1), 1-5.

Karimi, F., \& Akbari, M. (2013). Predicting organizational citizenship behavior on the basis of organizational learning capability. Middle-East Journal of Scientific Research, 18(9), 1371-1379.

Lin, H. F., \& Lee, G. G. (2004). Perceptions of senior managers toward knowledge-sharing behaviour. Management Decision, 42(1), 108-125. https://doi.org/10.1108/00251740410510181

Ramasamy, M., \& Thamaraiselvan, N. (2011). Knowledge sharing and organizational citizenship behavior. Knowledge \& Process Management, 18(4), 278-284. https://doi.org/10.1002/kpm.385

Robbins, S. P., \& Judge, T. A. (2013). Organizational behavior. New Jersy, NJ: Pearson Education Inc.

Schappe, S. P. (1998). The influence of job satisfaction, organizational commitment, and fairness perceptions on organizational citizenship behavior. The Journal of Psychology, 132(3), 277-290. https://doi.org/10.1080/00223989809599167.

Shafazawana, M. T., \& Dan Ying, C. Y. (2016). Managing Job Attitudes: The Roles of Job Satisfaction and Organizational Commitment on Organizational Citizenship Behaviors. Procedia Economics and Finance 35, 604-611.

Sorakraikitikul, S., \& Dan Siengthai, S. (2014). Organizational learning culture and workplace spirituality Is knowledge-sharing behavior a missing link? The Learning Organization, 21(3), 175-192. https://doi.org/10.1108/TLO-08-2011-0046

Teh, P.L., \& Sun, H. (2012). Knowledge sharing, job attitudes and organisational citizenship behaviour. Industrial Management \& Data Systems, 112(1), 64-82. https://doi.org/10.1108/02635571211193644

Teh, P. L., \& Yong, C. C. (2011). Knowledge sharing in is personnel: Organizational behavior's perspective. Journal of Computer Information Systems, 51(4), 11-21.

Ueda, Y. (2012). Effect of job involvement on importance evaluation of organizational citizenship behavior. International Journal of Business and Society, 13(1), 77-89.

Xue, Y., Bradley, J., Liang, H. (2011). Team Climate, Empowering Leadership, And Knowledge Sharing. Journal of Knowledge Management, 15(2), 299-312. https://doi.org/10.1108/13673271111119709

\section{Copyrights}

Copyright for this article is retained by the author(s), with first publication rights granted to the journal.

This is an open-access article distributed under the terms and conditions of the Creative Commons Attribution license (http://creativecommons.org/licenses/by/4.0/). 